hauptenden die Beweislast treffe (s. S. 278). Mir scheint es deutlich, dass man hier nicht vom Einzelfalle ausgieng, sondern eine allgemeine Anschauung zu Grunde legte, die dem Einzelfalle angepasst wurde.

Aus diesen Wurzeln ist dann wohl die Auffassung erwachsen, die das classische Darlehensrecht vollständig aus den Angeln hob. Dass dabei die „elenden Schuldner" wesentlich erleichtert wurden, war eine den menschenfreundlichen Kaisern willkommene Nebenwirkung.

\title{
VIII. \\ Die Ueberlieferung der Adressaten in Haloanders Ausgabe des Codex lustinianus.
}

\author{
Von \\ Herrn Professor Paul Krüger \\ in Bonn.
}

Die Bedeutung der Ausgabe Haloanders für die Kritik des justinianischen Codex liegt bekanntlich in der Benutzung des Egnatianus, einer seitdem verschollenen Handschrift der ersten neun Bücher. Aus ihr konnte Haloander fast sämmtliche Subscriptionen dieser Bücher entnehmen, während in den noch vorhandenen vollständigen Handschriften derselben Bücher, auf denen heutzutage die handschriftliche Ueberlieferung vorwiegend beruht, den sogen. Bononienses oder Vulgathandschriften ${ }^{1}$ ) sich nur ganz vereinzelte Subscriptionen finden und in den Handschriften des verkürzten Textes, welchen ich Epitome aucta genannt ${ }^{2}$ ), die Subscriptionen häufig stark verstümmelt, auch in den ersten vier Büchern oft an falscher Stelle eingetragen $\operatorname{sind}^{3}$ ). So ist es gekommen, dass abgesehen von

1) Meine Vorrede zum Codex Iustinianus S. XIX. - ${ }^{2}$ ) Ehenda S. XVIII. - ${ }^{3}$ ) Auch bei Haloander finden sich unvollständige Subscriptionen, einzelne fehlen ganz; zweifellos sind auch einzelne Lücken namentlich in den Consulaten von Haloander ausgefüllt. Trotzdem 
den Theilen, welche in der Veroneser Handschrift erhalten sind, und denjenigen Constitutionen, welche sich im Codex Theodosianus wiederfinden, Haloanders Ausgabe die Hauptquelle für die Subscriptionen bildet. Um dieses Vorzuges willen haben die früheren Herausgeber geglaubt, die Ausgabe Haloanders auch für den Text und die Inscriptionen der Constitutionen zu Grunde legen zu müssen; erst Herrmann ist davon merklich zurückgekommen.

In der Kritik des justinianischen Codex S. 71-79 habe ich dann nachgewiesen, dass Haloander für den Text der Constitutionen ausser der ersten Nürnberger Ausgabe von 1477, welche ihm als Druckexemplar gedient zu haben scheint, die übrigen Ausgaben seiner Zeit benutzt hat, dass dagegen eine Benutzung des Egnatianus entweder nicht stattgefunden hat oder jedenfalls so spärlich, dass wir überall im Zweifel bleiben, aus welcher Quelle Haloander geschöpft hat.

Für die Inscriptionen suchte ich das Verhältniss von Haloanders Ausgabe zum Egnatianus dadurch klarzustellen, dass ich zunächst für diejenigen Abschnitte, welche im Egnatianus fehlten, die sonstigen Hülfsquellen Haloanders für die Bearbeitung der Inscriptionen ausfindig zu machen unternahm. Die Ausgaben vor Haloander hatten die Inscriptionen, soweit sie sich nicht auf Imp. und Idem beschränkten, aus der Nürnberger Ausgabe von 1477 entlehnt, einzelne Ausgaben jedoch mit Nachträgen und Verbesserungen, welche aus Handschriften entnommen waren. Es zeigte sich num, dass Haloander theils an der Nürnberger Ausgabe festgehalten, theils die späteren Ausgaben benutzt hat; daneben steht noch eine Reihe selbständiger Lesarten Haloanders. Soweit nun die letzteren sich auf die Angabe der Kaiser beziehen, tritt klar zu Tage, dass Haloander vorwiegend mit Rücksicht auf die zeitliche Reihenfolge mehr oder minder glücklich geändert hat. Auch bei den Adressaten liessen meine Probevergleichungen einzelne Conjecturaländerungen erkennen; ob Haloander neben den Ausgaben auch Handschriften benutzt hat, darüber kam ich zu keinem sicheren Ergebniss.

kann man mit Sicherheit annehmen, dass die Zerrüttung der Subscriptionen im Egnatianus nicht so weit cediehen war wie in den Handschriften der Epitome aucta. 
Im Vergleich damit trat in einem zur Probe ausgewählten Abschnitt aus dem 5. Buch, welcher im Egnatianus vorhanden war, die handschriftliche Grundlage für eine Reihe selbständiger Lesarten zweifellos hervor, aber doch in so beschränktem Masse, dass ich Zweifel hegte, ob darin überall eine Benutzung des Egnatianus zu erblicken sei. Da nun in den heut zu Gebote stehenden Handschriften die Lesarten Haloanders mit wenigen Ausnahmen wiederkehren, und wir aus diesen den Werth der Ueberlieferung sicherer als aus der Ausgabe Haloanders zu bestimmen vermögen, so schien mir eine vollständige Benutzung der selbständigen Lesarten Haloanders hinsichtlich der Inscriptionen für eine kritische Ausgabe weder geboten noch nützlich ${ }^{1}$ ).

Dies Ergebniss, welches ich in meiner Bearbeitung des Codex festgehalten habe, ist von Mommsen im 12. Bande dieser Zeitschrift S. 150 angefochten worden. Seine Probevergleichungen von Codex 7, 1-4 als Abschnitt, für welchen der Egnatianus versagte, und 9,1-44 als Abschnitt, für welchen derselbe benutzt werden konnte, ergaben zwar für ersteren Abschnitt übereinstimmend mit meiner Auffassung den $Z$ weifel, ob hier handschriftliche Ueberlieferung mitbenutzt worden, dagegen für den anderen Abschnitt eine zweifellose und reichliche Benutzung einer guten Handschrift; dieser Gegensatz konnte nur durch den Egnatianus hervorgerufen sein. In einigen Lesarten glaubt Mommsen sogar gegenüber den von mir benutzten Handschriften die bessere Ueberlieferung erkennen zu müssen; daraus wäre der Schluss zu ziehen, dass die Ausgabe Haloanders für die Kritik der Inscriptionen in weiterem Masse, als in meiner Ausgabe geschehen, hätte herangezogen werden müssen.

Dem gegenüber ist zunächst hervorzuheben, dass gerade die beiden Hauptbeweisstücke Mommsens, die Zusätze et aliis in 9, 1, 11 und Asiae in 9, 44, 1 (= Cod. Theod. 9, 36, 1) weder echt noch aus dem Egnatianus entnommen sind. Den letzteren Zusatz hat Haloander aus der Ausgabe des Theodosianus von Sichardus (1528) entlehnt, während alle von Hänel und mir verglichenen Handschriften des Theodosianus, darunter

1) Vgl. Kritik des just. Codex S. 81 f.

Zeitschrift fïr Rechtsgeschichte. XIII. Rom. Abth. 
der Turiner Palimpsest und der Vaticanus Reg. 886, mit der handschriftlichen Ueberlieferung des justinianischen Codex übereinstimmen. Auch steht dem Zusat\% entgegen, dass noch 2 Monate vorher (VIII id. Mai.) Menander als Vicarius Asiae bezeugt ist (Cod. Theod. 9, 39, $2=$ Cod. Iust. 9, 46, 8) und dass die Constitution aus 'Trier datirt ist ${ }^{1}$ ). Der Zusatz et aliis dagegen ist reine Vermuthung Haloanders, gestützt darauf, dass der Text der Konstitution die Anrede in der Mehrheit gebraucht. Haloander hat bei allen gleichartigen Rescripten, wenn nur ein Adressat überliefert war, den obigen aus anderen Konstitutionen bekannten Zusatz als vermeintlich ausgefallen ergänzt $^{2}$, nämlich in $2,24,1.2,25,1$. 2, 26, 4. 3, 8, 1. 3, $28,23$. 3, 32, 17. 3, 38, 6. 8. 4, 29, 17. 4, 44, 7. 4, 65, 14. 5, 28, 3. 5, 51, 6 . $5,62,18$. $6,27,2$. $6,37,15.8,17,2$. $\left.8,23,1.8,44,28.8,51,1^{3}\right)$. Hiervon fallen 4, 44, 7. 4, 65, 14 in einen der Abschnitte, welche der Egnatianus nicht enthielt; in 2, 25, 1 widerlegt 4, 51, 4 den Zusatz; in 5, 62, 18 liegt ein grobes Versehen Haloanders vor, da nur der Schluss scheinbar mehrere anredet (ad excusandos uos a tutela), während es vordem heisst: licet non appellasti, si quam te excusationem habere confidis - hac - uti non prohiberis. Wie dieses Rescript und andere (z. B. 5, 28, 3. $8,8,3)$ zeigen, hat Haloander übersehen, dass, wenn in Rechtsstreitigkeiten, welche mehrere Personen gleichmässig berührten, nur eine derselben sich an den Kaiser wendet, das Rescript doch uiber die Stellung aller sich aussprechen muss. Dazu kommt, dass auch bei einer Mehrzahl von Anfragenden das Rescript bisweilen in der Adresse nur einen derselben nannte ${ }^{4}$ ). In einzelnen der obigen Konstitutionen mag auch der scheinbare Widerspruch zwischen Adresse und Anrede dadurch hervorgerufen sein, dass der Name des zweiten Adressaten in der Ueberlieferung ausgefallen ist, wie es nachweislich in $4, \mathbf{3 1}, \mathbf{1 1}$. 4, 39, 3. 4, 54, 4. 8, 41, 1 geschehen ${ }^{5}$ ).

1) In Trier hielt sich damals der Gegenkaiser Maximus auf, während Valentinian in Mailand, Theodosius in Konstantinopel sich befand. Wie die darauf hin erbobenen Bedenken gegen die Ueberlieferung zu beseitigen sind, lasse ich dahingestellt. - ${ }^{\text {q) }}$ Dass et aliis bisweilen aufgefallen ist, mochte Haloander $z$. B. aus 3, 13, 1. 6, 2, 16 entnehmen. - ${ }^{\text {a) }}$ Vgl. die Vorrede zu meiner Ausgabe S. XXIV Anm. 7. Umgekehrt hat Haloander den schon in der Nürnberger Ausgabe gemachten Zusatz gestrichen in 6, 49,3. - 4) Cod. 1, 23, 1. - 5) Vgl. z. B. 
Auch darin weiche ich von Mommsen ab, dass ich den Egnatianus bloss um der Subscriptionen willen nicht als die zweifellos beste der für unseren Text benutzten Handschriften gelten lassen kann. Ich halte es nicht für undenkbar, dass wie in einzelnen der vollständigen Handschriften des 11. und 12. Jahrhunderts sich noch mehr oder weniger Subscriptionen finden, so auch eine Handschrift derselben Klasse die Subscriptionen vollständig aus dem zur Ergänzung der Epitome benutzten Archetypon übernommen habe. Alsdann würden die Subscriptionen ebenso wenig den Vorrang des Egnatianus vor den übrigen Handschriften derselben Gruppe beweisen, wie unter den noch vorhandenen Handschriften das Mehr oder Minder von Subscriptionen über die Reinheit des übrigen Textes entscheidet ${ }^{1}$ ). Gerade dass Haloander am Egnatianus nur die Sorgfalt in der Ueberlieferung der Kaisernamen lobt (imperatorum nomina diligenter descripta), dagegen von den Adressaten schweigt, führte mich darauf, anzunehmen, dass der Egnatianus hinsichtlich der Letzteren vielleicht noch den von mir benutzten Handschriften dieser Klasse nachstand. Wir hätten dann an ihm eine volle Parallele zu den Handschriften der letzten 3 Bücher, aus welchen Contius und $\mathrm{Cu}$ jacius die Subscriptionen ergänzt haben ${ }^{2}$ ). Die Ueberlieferung der Adressaten durch Haloander wird uns einer Lösung dieser Streitfrage näher bringen.

Um nun das Verhältniss von Haloanders Ausgabe zum Egnatianus festzustellen, müssen wir zunächst die Beschaffenheit der Ausgabe in denjenigen Theilen, welche im Egnatianus fehlen, ins Auge fassen. Mommsen hat dafür 7, 1-4 gewählt; hier sollen aus den Titeln 4, 30-38 alle Abweichungen Haloanders von der in meine Ausgabe übergegangenen handschriftlichen

$3,32,17$, (contra quem preces funditis) 5, 51, 6. In 5, 71,2 hat Haloander et aliis eingesetzt statt des zweiten Adressaten, den die Nürnberger Ausgabe richtig wiedergegeben hatte. In einigen Konstitutionen ist schon vor Haloander ein zweiter Adressat zugesetzt werden, z. B. 2, 4, 34. $5,56,4.6,50,7$.

1) Unter den von mir benutzten vollständigen Handschriften der ersten 9 Bücher hat die Handschrift von Montpellier die meisten Subscriptionen, während sie sonst an kritischem Werth die letzte Stelle einnimmt und insbesondere die Inscriptionen am unvollkommensten wiedergiebt. - ${ }^{2}$ ) Vgl. die Vorrede zum Codex S. XII. 
Ueberlieferung oder von der Nürnberger Ausgabe zusammengestellt werden. Die letztere bezeichne ich durch Nor.; die Lesarten der an diese sich anschliessenden und sie theilweise bessernden Ausgaben sind aus der Ausgabe von Fradini 1512 (= Frad.) entnommen. Für die Handschriften sind die in meiner Ausgabe benutzten Zeichen beibehalten; wo diese fehlen, stimmen die Handschriften mit der vor der eckigen Klammer stehenden Lesart.

4, 30, 1 hilaro] hilario Nor. Hal.

3 demetriae] demetrio Nor. Hal.

4 basso] Nor., bassano Hal.

4, 30, 5 augustino] haustiano Nor. Hal.

6 iustino] Frad. Hal., instino Nor.

7 ammoniano SR Nor., thanniano $\mathrm{P}$, ammiano C Hal.

9 zoilo] Hal., zoelo Nor.

10 mucazano] mazantio Nor. Hal.

4, 31, 2 asclepiadi $\mathrm{C}$, asclepiadae $\mathrm{S}$ Nor. Hal.

6 polydeucae] pollidenti Nor. Hal.

7 ausonio] eudoxio Nor., eusosio Frad., euzosio Hal.

9 euctemonidi] emenidi Nor., eumenidi Hal.

10 nicandro] Frad. Hal., oritanto Nor.

11 iulio] iuliano Nor. Hal.

4, 32, 4 honoratae] honorio Nor. Hal.

6 antigono] antiaeneo Nor. Hal.

8 doryphoro] deforo Nor., theophoro Hal.

11 popilio] Hal., populo Nor.

13 eustathiae] eustachiae Nor. Hal.

14 aurelio] Frad. Hal., auxilio Nor.

17 euxeno] Frad. Hal., auxeno Nor.

19 irenaeae] hyereneyae Nor., hyerenne Frad., hyreniae

Hal.

21 chresimoni] Nor., chresimo Hal.

24 culciae] gluciae Nor., glauciae Hal.

4, эз, 1 honorato] Hal., honoratico Nor.

a cosmianae] cosimaniae Nor., chosimaniae Hal.

3 iulianae] iuliae Nor. Hal.

4, 34, 1 mestrio] mesteno Nor., mestaeno Hal.

2 celsino] caelso Nor., celso Hal.

3 austronio] austero Nor. Hal. 
4, 34, 4 timocrati] Hal., timograti Nor.

$s$ claudio] claudiano Nor. Hal.

9 menophilo] menosilo Nor., nenofilo Frad., menophyllo Hal.

10 septimiae] septimae Nor. Hal.

$11 p p$. fehlt in Nor. Hal.

$4,35,2$ marcellino] marcello Nor. Hal.

$s$ iuliano] guliano Nor. Hal.

13 zosimo] Hal., zosmio Nor.

15 precario] Nor., precatio Frad. Hal.

16 uzando] uiando Nor., uranio Hal.

22 eustathio] S, eustachio C Nor. Hal.

4, 37, 2 pannonio] pantoni Nor., pantonio Hal.

4, 38, 7 isioni] hisoni Nor., pisoni Hal.

10 gordianae] gorgio Nor., georgio Hal.

11 paterno] Nor., paterio Hal.

12 paciano] paterno Nor. Hal.

13 lolliano] iuliano Nor. Hal.

14 illyrici] Nor., illyrici et italiae Hal. ${ }^{1}$ ).

Die Abweichungen Haloanders von den älteren Ausgaben beruhen theilweise auf Konjecturen; so in 4, 30, 9. 4, 31, 7. 9. 4, 32, 8. 19. 21. 24. 4, 34, 4. 9. 4, 35, 13. 4, 38, 7. 10, dagegen lassen diejenigen in $4,30,4.7 .4,32,11.4,33,1.4,35,16.4,38,11$ eine solche Erklärung wohl nicht $\mathrm{zu}$, sondern scheinen auf handschriftliche Ueberlieferung zurückzuführen.

Als Gegenstück wählte Mommsen aus den Abschnitten, welche in Egnatianus vertreten waren, die Titel 9, 1-44. Dass er für diese zu einem wesentlich anderen Ergebniss kam, als ich mit dem Abschnitt aus dem 5. Buch, beruht zunächst auf der verschiedenen Beschaffenheit der Adressen dieser beiden Abschnitte in den älteren Ausgaben. Vom Ende des 8. Buches bis in den Anfang des 9. und dann wieder vom 23. Titel bis ans Ende dieses Buches geben diese die Adressen theils stark verdorben, theils in unsinniger Weise abgekürzt wieder, lassen sie auch vielfach ganz weg; somit fand Haloander hier reiche Gelegenheit aus dem Egnatianus oder aus anderen Handschriften oder auch durch selbstgefundene Besserungen nach-

1) Der Zusatz ist aus dem Codex Theodosianus von Sichardus 1528 entlehnt. 
zuhelfen. Umgekehrt sind gerade im 5. Buch die Adressen durch die älteren Ausgaben besser als in den meisten übrigen Theilen überliefert.

Um ein nicht durch derartige Zufälligkeiten beeinflusstes Bild von der Benutzung des Egnatianus in Haloanders Ausgabe und eine sichere Grundlage für die Werthschätzung des Egnatianus zu gewinnen, bleibt nichts übrig, als für die gesammten in dem letzteren vertretenen Abschnitte die Haloanderschen Lesarten denen der älteren Ausgaben und der handschriftlichen Ueberlieferung gegenüberzustellen. Die bereits angestellten Untersuchungen gestatten eine wesentliche Vereinfachung dieser Zusammenstellung durch Ausscheidung aller derjenigen Stellen, in welchen Haloander zwar von der handschriftlichen Ueberlieferung abweicht, aber mit einer der älteren Ausgaben übereinstimmt. Ferner genügt für diejenigen Adressen, in welchen Haloanders selbständige Lesarten gleichlautend sind mit der handschriftlichen Ueberlieferung, die folgende Tabelle. Wo die Bestätigung sich auf einen Theil der Adresse beschränkt, gebe ich diesen in der Klammer an. Weggelassen habe ich diejenigen Stellen, in denen eine Aenderung del früheren Lesarten im Wege der Konjecturalkritik so leicht war, dass der Annahme einer Benutzung von Handschriften jede Stütze fehlt. Einige derartige öfter wiederkehrende Aenderungen, welche auch da sich finden, wo der Egnatianus versagte, sind z. B. quirillo in cyrillo, erythio oder eritirio in erythrio, euticiano in eutychiano, euagium in euagrium. Da eine feste Grenze nach dieser Seite hin nicht zu ziehen ist, so habe ich im Zweifel auch derartige Stellen mit aufgefuihrt.

\section{Buch I}

4, 3. 8. 19. 5, 3. 10. 6, 2. 7, 2. 9, 1. 3-6. 16. 11, 2. 5. 6. 12, 1. 6. 14, 9 (рp.). 16, 1. 18, 2. 4-6. 8. 11-13. 19, 1. 21, 1. 22, 2.4. $23,1-3.26$, 3. 4. 24 , 1. 2. 26, 3. 4. 27, 2. 30, 2. 31 , 4. 5. 32,1 . $33,1-3.35,1.37,1$. 39, 2. 40,4 . 10. 12. 13. 43,1 . 46, 4. 47, 1 (pp.). 50, 2. 51, 10. 11. 52, 1. 54, 1 (pp.). 5. 55, 1. 56, 1.

\section{Buch II}

1, 3. 5. 7. 3, 1. 10. 12. 17. 21. 22. 27. 4, 3. 4 16. 25. 40 (pp.). 7, 5 (pu.). 6. 9. 11. 17. 24. 8, 3. 4. $11,9.14 .12,16.17 .24 .25 .14,1$ (pp.). 18, 17. 
19, 7. 20, 3. 21, 3. 23, 1. 24, 2. 28, 1. 30, 3 (Sabinillae). 33,1 . 35, 1. 37, 1. 38, 1. 50, 1. 53, 1. 3-5. 57, 1. 2 .

\section{Buch III}

1, s. 2, 1. 3, 1. 5, 1 (pu.). 7, 1. 11, 2. 6. 12, 2. 6 (Luciano). 13 , 1. 3. $22,1.24,1.26$, 3. 7. 11. 28, 2. 12 (Liciniano). 29, 5. 7. 30, 1. 31, 1. 4. 7-9. 11 (Asiae). 32, 1. 5. 8 (militi). 18. 20. 23. 33, 6. 7 (militi). 9. 12 (pp.). 15. 34, 3. 7. 8. 10. 38, 1. 2. 7. 39, 3. 5. 42, 2. 4. 5. 44,9 .

\section{Buch IV}

1, 3. 2, 6. 7. 5, 5. 7, 1. 10, 1. 5. 13,2 .

\section{Buch V}

$12,1.9 .13 .14 .24 .28 .14$, 2. $15,2.16$, 7. 19. $18,8.28$, 2. 29 , 4. $31,1$. 2. 37, 3. 38. 38, , $42,4 . \quad 43$, 1. 9. 46, 1. 52, 2. 53 , s. $54,1.2 .56$, 3. $58,2.61,2.62,1$. 2. 14. 16. 18. 64, 1. 2. 69,1 . 70, 4. $71,8.11 .72,3.74,4.6$.

\section{Buch VI}

1, 1. 2. 6. 2, 3. 13. 20. 22. 3, 5. 7. 13 (pp.). 6, 8. 7, 2. 13, 2 (Asclepiodoro). 15, 1. 18, 1 (pp.). 20, 6. 9. 11. 21, 16. 22, 1. 2. 23, 3. 8. 23. 25 , 2. 26 , 3. 6. 28 , ว. 30 , з. 4. 31 , 2. э. 33 , э. $34,1.35$, 2. 3. 7. 36,1 . 3. 4. $37,12.13 .42$, 2. 3. 10. $17-20.44$, s. 47 , 2. 49 , 1. 3. 4. $50,4.10 .13 .16 .53,4.54,4$. 55, в. 10. 11. 56, 3. 6 (рp.). 57, 1. 4. 58, 1. 2. 6. $59,6.60$, 1. 4. 61, 1. 3. 6.

\section{Buch VII}

73, 6. 7. 75, 3. 5. 6 .

\section{Buch VIII}

1, 4. 2, 3 (Petronio). 4, 4. 8. 5, 2. 7, 1. 9, 1. 2. 5. 6. 9. 10. 11, 1-3. 9. 13. 14. $13,13.15 .18 .15,3.16,5.17,2$ (Chresto). 5. 9. 17, 11. 18, 1. 4. 19, 1 (Athenioni). 22, 1. 24, 1. 25, 4. 27, 11-13. 16. 17. 29, 3. 4. 35 , 1. 2. 9. 13. 36, 3. $37,1.6 .10 .13 .38,1$. 3. 4. 39 , 3. 4. 40 , 5. 12. 17. 23-25. 28. 41, 4. 5. 42, 3. 4. 13. 16. 23.24. 43, 1. 44, 7. 11. 18-21. 28 (Maximiano). 29. 46, 2. 7-10. 47, 1. 4. 7. 48, 2. 4. 49, 1 (pu.). 50,1-5. 10. 11. 17. 19 (ducem). 20. 51, 2 (pp.). $52,1.53,3.10 .13 .15-19.22-28$ (pp.). 29-31 (pp.). 32 (pp.). 34 (pp.). 54, 1. 55, 4. 7. 8. 56, 3. 4 (pp.). 57, 2 (pu.). 58, 1 (pu.). 2.

\section{Buch IX}

1, 1. 2. 5. 11 (Saturnino). 12. 13. 17. 19 (praesidi). 21. 2, 1. 3. 6. 9.13. 14. 17. 3, 1-3. 4 , 1. 3. 5, 1. 6, 4. 7, 1. 8, 2. 3 (pu.). 4 (pu.). 5. 
9, 1-3. 5. 9. 12. 17. 19. 20. 26 27. 31. 12, 2. 4. 5.9(pp.). 16, 1. 9. 17, 1. 18, 8. 19, 2 (pp.). 3. 20, 7 (pu.). 9. 10, 15, 16. 22, 5, 14. 15. 19. 22 (pu.). 23 (pp.). 24 (pu.). 23, 2. 3. 6. 24, 1. 3 (pp.). 26, 1. 27, 1-3. 5. 28, 1 (pp.). 29, 2 (pu.). 31, 1. 32, 1. 3. 6. 33, 3. 5. 34, 2. 35, 1 . 3. 8. 9. 11 (uiro illustri). 36, 1. 38, 1. 39, 1. 2 (pp.). 40, 3 (pp.). 41, 5. 6. 9 (praes. Syriae). 10. 12. 42, 1. 2. 43, 1.

Ich lasse mun die Zusammenstellung der übrigen selbstständigen Lesarten Haloanders folgen. Hierbei soll regelmässig nicht der ganze handschriftliche Apparat meiner Ausgabe wiederholt werden, sondern nur die Lesarten der Hauptvertreter jeder einzelnen Handschriftenklasse; wo jedoch die Lesarten der Handschriften zweiten Rangs mit denen Haloanders verwandt sind, werden sie mit angefülırt.

1, 4, s gennadio] SCR Th., emadio Nor., eutychiano Hal.

1, 5, 1 dracilianum] S Th., gratilianum $\mathrm{P}^{\mathrm{b}}$ Nor., gracilianum

$\mathrm{R}$ Hal., gracillianum $\mathrm{C}$.

2 hesperium] CR Th. Nor., speriumb S, hesperidum Hal. 4 senatori] SR Th., senetioni Nor., ad senatorem C Hal. - leontio] SCR Th. Nor., ad leontium Hal. pur.] W Lips. Th. Hal., pp. SR Nor., pp. urbis C.

12? imp. iustinianus a. demostheni pp. Hal. ${ }^{1}$ )

19 demostheni] SCR Nor., iuliano Hal.

1, 6, 3 florentio] SCR Th., ad floren. Nor., ad florenti. Frad., floriano Hal.

1, 7, 1 ad thalassium] CR Th., $a d^{2}$ ) tauro S (vgl. 1, 6, 3 subscr. felice et tauro conss.), ad phalasum Nor., ad taurum Hal.

s flauiano] SCR Th., fabiano Nor., fahiano Hal.

1, 9, 1 tryphonino] S Hal., trifonio C R, ystrophonio Nor.

12 ionio] CR, iobio S, ionio Nor., iouino Hal. iohanni] SCR, eidem ionio Nor., iouino Hal.

1, 12, 2 iouio] Th., iouiano $\mathrm{S}$, iobio $\mathrm{C}$, oberio $\mathrm{R}$, ionio Nor., iouino Hal.

4 hierio] Th., hemerio $\mathrm{S}$, imerio $\mathrm{C}$, erminio $\mathrm{R}$, crimo Nor., erimio Frad., imperio Hal.

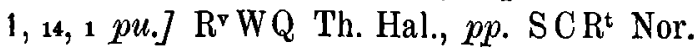

1) Vgl. meine Ausgabe S. 79 zu Zeile 29; die Inscription gehört vielleicht zu c. $19 . \quad{ }^{2}$ ) Dies ad ist in meiner Ausgabe ausgefallen. 
Die Ueberlieferung der Adressaten im Cod. Iust.

1, ${ }_{14}, 9$ pp.] SM Hal., fehlt in CR Nor.

1, ${ }_{18,2}$ imuenali $\mathrm{CR}^{\mathrm{b}}$ Hal., iunenili $\mathrm{SP}$, iunenali $\mathrm{R}^{\mathrm{a}}$, iuliano Nor.

10 amphiae S PCR, philippo Nor., araphiae Hal.

1, 19, 2 pu.] T Th. Hal., pp. SCR Nor.

4 floro] P Th., florentio SR, florentino C, flo. Nor., floriano Hal.

6 pu.] CR Hal., pp. S Frad.

1, 22, 1 aa. et cc. gregorio] PCR Nor., aa. gregorio $\mathrm{S}$, aa. consulibus graecorum Hal.

3 bassum SPCR Nor., bassum p. p. Hal.

1, 23,5 nicetium $\mathrm{SC}$, uincentium $\mathrm{P}$ Nor. ${ }^{1}$ ), nicentium $\mathrm{R}$, uicenum M Hal.

1, 24, 4 nomum] SW Hal., anomum $\mathrm{C}$, nonium $\mathrm{R}$, nomtum Nor.

1, 29, 1 eusignium] SCR, eusi. Nor., eugenium Hal.

5 et gentes] CR Frad., et ceteras gentes Hal., fehlt in Nor. 1, 40, 2 maximum] SPC R Th., max. Nor., maximiunum Hal. 5 apronianum] M Hal., probianum $\mathrm{S}$, apromatum $\mathrm{P}$, pronianum $\mathrm{CR}$, prouianum Nor.

12 monaxio] SC, monachio R Hal., cronasio Nor.

15 idem a. (= imp. leo a.) constantio pp.] SCM Nor., imp. anastasius a. uiuiano pp. Hal.

1, 43, 1 nebridio] nibridio $\mathrm{M}$, nebrio $\mathrm{S}$, neindrio $\mathrm{CR}$, nebrideo Nor., nephridio Hal.

1, 46, 2 monaxio] SM, manasio C, moanasio $\mathrm{R}$, maximo Nor., monachio Hal.

1, 48, 2 ad principium pu. (p. M)] M Nor., principibus pu. $\mathrm{S}$, ad principem pum $\mathrm{P}$, ad principes populi $\mathrm{CR} \mathrm{Hal}$. 3 pp.] SCR Th. Nor., praeposito Hal.

1, 50,2 ad antiochum $p p . \mathrm{M}$, anticho $p p$. S., antiocho $p p . \mathrm{CR}$, antiochum $\mathrm{P}$, antiochio pp. Nor., antiocho ceterisque pp. Hal.

1, 51, 2 pp. CR Nor., pu. S W Hal.

1, 54, a decimo] SW Nor., deciouo $\mathrm{CR}$, decimio $\mathrm{M}$, decimio $p p$. Hal.

3 celeri] SCR Nor., celeri $p p$. Hal.

1) Auf Ragonius Vincentius Celsus (Corp. inscript. Lat. VI, 1 n. 1759/60) bezieht diese Konstitution Hirschfeld röm. Verwaltungsgeschichte 1, 135, 2. 
1, 55, 4 defensori (defensor $\mathrm{S}$ ) ciuitatis] $\mathrm{S}^{1}$ ) CR Frad., pp. Nor., defensori Hal.

2, 2, 1 a. triphoni $\mathrm{S}$, a. trrifino $\mathrm{P}$, a. trophimio $\mathrm{CR}^{2} \mathrm{Hal}$., atiphiniae Nor.

2, 3, 9 mucatrauli $\mathrm{S}$, mucratauli $\mathrm{P}$, mucrataulio $\mathrm{CR}$, mucracaulio Nor., mucatraulio Hal.

10 a. nicae $\mathrm{M} \mathrm{Hal}$, a. nige $\mathrm{S}$, a. niche $\mathrm{pCR}$ Frad., amitae Nor.

14 caecilio S P Nor., caelio CR Hal.

15 pactumeio G Bamberg. Hal., menio W Nor., fehlt in $\mathrm{SpCR}$.

25 euthemero R Hal., eumero SC Nor., euchemero P.

2, 4, 13 proclae $\mathrm{PCR}$ Nor., procule $\mathrm{S}$, prode $\mathrm{L}$, probae Hal.

19 irenaeo C Hal., hereneo S, ireno PR Nor.

${ }_{25}$ marcellae et cyrillae (quirillae $\mathrm{C} \mathrm{Hal}$. )] $\mathrm{C} \mathrm{W} \mathrm{Hal.,} \mathrm{mar-}$ cellae Sp, sabinae et marcel. Nor.

26 dionysiadae $\mathrm{M}^{\mathrm{b}}$ Hal., dionisie $\mathrm{SG}$ Nor., dionisie de $\mathrm{PR}$. 28 sapparutae $\mathrm{C}$, saffatrute $\mathrm{S}$, apparute $\mathrm{R}$, sapparitae Hal., appitae Nor.

so antonino SC Hal, antonio PR Nor.

33 euchrusio C Hal., eucrasio S, eucheriffio R, euchiriphio Nor.

34 phtolomaidae $\mathrm{S}$, palomaidi $\mathrm{C}$, tollomaidi $\mathrm{M}$, cyvillo phitolemaidi R, cerillo et ptolomaydi Nor., cyrillo et ptholomay. Frad., cyrillo et ptolemaidi Hal.

ss ammonio $\mathrm{M}$, admonio $\mathrm{S}$, hamoniti $\mathrm{P}$, ammoniti $\mathrm{R}$, ammonito Nor., hammoni C Hal.

${ }_{36}$ achilleo $\mathrm{PR}$, anchylleo $\mathrm{S}$, ancille $\mathrm{C}$, archileo Nor., achillae Hal.

38 theodotiano $\mathrm{P}^{\mathrm{b}} \mathrm{R}$ Nor., theodosiano $\mathrm{S}$, theodotiono $\mathrm{Pa}$, theodatione $\mathrm{C}$, theodotioni Hal.

42 erythrio] S C Nor., erithirio P, enthrio $\mathrm{R}$, acrochirio Hal.

43 illyrici SPCR Frad., per illyricum Hal., om. Nor.

2, 6, theodotiano PCR Nor., theodatiano S, theodotioni Hal.

5 helladio R Hal., belladio SC, beliano Nor.

2, 7, 1 doloni SC Hal., daloni D R Nor.

1) In meiner Ausgabe ist unrichtig angegeben, dass $S$ diese Worte weglässt; sie sind nur durch Versehen des Schreibers zum Anfang des darauf folgenden Textes gezogen. 
2, 7, 4 eustathio] S Hal., eustachio PR Nor., estachio C, eustasio M Th.

14 callicrati] L M Hal, callicatri $\mathrm{Sp}$, calliorati CR, calliorato Nor., calligrati Frad.

16 pu.] S Lips. 1? Bamberg.? Hal., pw. C R, om. Nor.

23 eustathio] SM Hal, eustachio CR Nor.

25 marino] $\mathrm{M}^{\mathrm{b}} \mathrm{Q}$ Hal., marono $\mathrm{R}$ Nor., martiano $\mathrm{S}$, matrono $\mathrm{C}$, amarino $\mathrm{W}$.

2, 11, 1 manilio] QW Greg. (Collectio III pag. 253) Hal., magnualio A, manualio SCR Frad., mutualio Nor.

2 uerennio $\mathrm{C}$, uerenio Hal., sereno $\mathrm{S}$, erennici $\mathrm{R}$, herennio Nor.

3 metrodoro SCR Nor., ad metrodorum Hal.

11 irenaeo $\mathrm{M}$, erineo $\mathrm{S}$, herino $\mathrm{R}$ Nor., herennio $\mathrm{C}^{\mathrm{b}} \mathrm{Hal}$.

13 iucentio SM, iuuentino C, uiuentio R Nor., inuentio Hal.

15 sulpiciae C M Hal., ulpiciae S, supliciae pR Nor.

17 magno SCR Nor., ad magnum Hal.

20 fortunato] SA M Hal., furtuno PCR, furtino Nor.

2, 12, 1 seuero] W $Q^{b}$ Hal., seuerus a. S, seu. $\mathrm{P}$, seuerus $\mathrm{CR}$ Nor.

10 castriciae] SPCR Nor., castiae M Hal.

2, 16, 1 octauiano S P R Frad., octabio C, octauio M Hal,, octauia. Nor.

2 craugasio $\mathrm{S}$ Hal., graukasio $\mathrm{M}$, graucasio $\mathrm{W}$, grafio PCR, gragasio Nor., grasio Frad.

2, 17, 2 tertullo] SPM Hal., tertullio C R Nor.

2, 18, 4 claudio] SM Hal., glaudio C, graccho PR Frad., gladio Nor.

s trophimo] S, trophemo C, trophono $\mathrm{R}$, trophino Nor., tryphonio Hal.

14 rufo] SPCR Frad., roso Nor., mutiano rufo Hal. (vgl. c. 15).

15 muciano $\mathrm{SCR}$, munciano $\mathrm{P}$, muclano Nor., mutiane

Frad., eutychiano (aus c. 16) Hal.

21 mitrae $\mathrm{CR}$, metreae $\mathrm{S}$, matrae Nor., michrae Hal.

2, 19, 4 eutycheti] AC, eutichiti S, euthiceti Nor., euthichio PR, euthydico Hal.

- pollae CR Nor., pollie S Hal.

8 trophimo $\mathrm{R}$, trophimio $\mathrm{S}$, rophimo $\mathrm{C}$, trophinio Nor., triphonio Hal. 
2, 19, g hymnodae PR Hal., ymno S, hinnode C, humodae Nor. 2, 20, 5 aphrodisiae $\mathrm{R}$, phrodisiae $\mathrm{P}$, amphrodisse $\mathrm{C}$, ampirosae Nor., amphidrosae Hal.

6 hymnodae] C Hal., hynode $\mathrm{S}$, etymnodae PR, hummodae Nor.

2, 22, 1 candiano] PC Nor., candidiano $\mathrm{S}$, candido lex iungenda 4, 31, 1, cantiano R, gaudiano Hal.

2, 26, 1 iuliis] CR Nor., iulio $\mathrm{S}$, uiliis Hal.

3 aelianae] $\mathrm{C}$ Nor., alienae PR Hal., iulianae S.

4 urbano] PCR Nor., urbiano S, urbinio et aliis $\mathrm{Hal}$.

2, 28, 2 clementianae $\mathrm{PC}$, clementiae $\mathrm{R}$, dementianae Nor., clementinae Hal.

2, 29, 2 midae $\mathrm{C}$, mede $\mathrm{M}$ Nor., medie $\mathrm{S}$, dimidiae $\mathrm{PR}$, medeue Hal.

2, 30, 1 anniae] SCR, ad amniae M, hammae Nor,, hamniae Hal.

2 solanae] SC Nor., solariae R, solanie M, solaonae Hal.

3 marthonae LW Hal., marthoniac p?R, matrone SC Nor.

2, 31, 1 honorato] SPCR, honorio Nor., antonio Hal.

2, 32, 1 soteri SCR, sateri Nor., sotericae Hal.

2, 39, 2 sarapiadi $\mathrm{CR}$ Hal., sarapidi $\mathrm{S}$, serapiae $\mathrm{P}$, sirapi Nor.

2, 40, з decimo] SCR Nor., decimio Hal.

2, 42, 4 libio SCR labeo Nor., labio Hal.

2, 43, 3 aniciae $\mathrm{M}$ Hal., anicae $\mathrm{C}$, maniniciae $\mathrm{S}$, iniciae $\mathrm{R}$, amiciae Nor.

2, 44, 1 agathocleti $\mathrm{S}$ ? PR, gathocleti $\mathrm{C}$, gathadeti Nor., catholeti Hal.

2, 45, 2 sotheri SR, sortiri P Hal., sortiti C, sortaris Nor., sotari Frad.

2, 50, 3 flauio] SM Hal., flauiano C, florentio $\mathrm{R}$, flauiano et Nor.

4 mestriano] SCR, metriano Nor., mastriano Hal.

2, 52, 5 bassum] CR Th. Nor., bassum p. p. Hal.

2, 53,5 liciniano] S PM Hal., licimiano C, liconiano R, liciano Nor.

2, 57, 2 pp.] SCR Th. Nor., p. u. Hal.

2, 58, 2 iuliano] SPCR Nor.. iohanni Hal.

3, 1,6 iuniae] SPM ${ }^{\mathrm{b}}$ Hal., liniae $\mathrm{C}$, iunio $\mathrm{R}$, luniae Nor.

7 hyrenae $\mathrm{P}$ Nor., herine $\mathrm{S}$, hirennae $\mathrm{C}$, hireneae $\mathrm{R}$, hyrinae Hal. 
3, $1,10 p u$.$] P Lips. I? II? Th. Hal., p p$. SR, fehlt in C Nor. 3, 8, 2 magnillae $\mathrm{C}$ Hal., magnellue p Nor., agnelle $\mathrm{S}$, magniillae R.

4 calpurnianum] SC, calphurnianum R Nor., calphurnium Hal.

3, 11, 3 praefecto annonae] $\mathrm{C}$, praefecturio anone $\mathrm{S}$, pp. anone $\mathrm{M}$ Nor., pannone $\mathrm{R}$, p. pannonie Hal.

3, 12,4 pu.] CR, p.p. Nor., om. AS Hal.

3, 13, 3 iudae SFPCR Nor., iudee $\mathrm{M}$, iudaeae Hal.

3, 15, 2 nicae SF PCR, niciae Nor., niceae $\mathrm{M}$ Hal.

3, 18, 1 heraclidae P R Hal., eraclee $\mathrm{S}$, herucliae $\mathrm{C}$, heradidae Nor.

3, 21, 1 gerontio SM Hal., generatio P, gerentio C, genrentio $\mathrm{R}$, geruncio Nor.

3, 22, 1 aurelio] C Hal., aur. P M, fehlt in S A Nor. aristocrati $\mathrm{Hal}$., aristograti $\mathrm{ACR}^{\mathrm{b}}$ Nor., arestograti $\mathrm{S}$, aristogratis $\mathrm{P}$.

3 zezonide $\mathrm{S}$, zenoniae PCR Hal, henonidae Nor.

4 sisinniae $\mathrm{PR}$ Hal., sisinne $\mathrm{S}$, sifinniae $\mathrm{C}$, sunnae Nor.

3, 23, 1 pu.7 CR, pp. S Hal., praep. Nor.

3, 27, 2 hadriano] SPCR Nor., hadiano Hal.

3, 28, 12 diogeniano SPCR Frad., diogono Nor., diogeni Hal. 15 aphrodisiae $\mathrm{SPR}^{\mathrm{b}}$ Hal., astrodisiae $\mathrm{C}$, aflodisiae $\mathrm{R}^{\mathrm{a}}$, afflodisiae Nor.

16 theodotae SPCR, theodocio Nor., theodorae Hal.

20 sabiniano SC, sabinianae P, saluiano R., sabino Nor., sauiano Hal.

23 philippo SP Nor., philippae LCR, philippae et aliis Hal.

25 menedoto $\mathrm{C}$ Hal., menedote $\mathrm{SR}$, medato $\mathrm{p}$, monodoxo Nor.

26 salutem] SPCR Nor., s. d. Hal.

${ }_{27}$ ad lucrium uerinum $\mathrm{Th}$., ad uerinum $\mathrm{P}$ Nor., ad uerianum $\mathrm{S}$, uerino $\mathrm{ACR}$ Hal.

28 daciae] ASM Th. Nor., prouinciae PCR Hal.

3, 29, 1 papinianae $\mathrm{SP}^{\mathrm{b}} \mathrm{C}$ Nor., papianae $\mathrm{R}$ Hal.

2 aetiae] $\mathrm{APR}$, actiae $\mathrm{C}$, anthiae $\mathrm{S}$, eune Nor., aerine Hal. 
3, 31, 3 epictae] Sp C Nor., epictesidi $\mathrm{R}$, epictesi Hal.

10 theodotiano $\mathrm{C}$, therdationo $\mathrm{S}$, theodationo $\mathrm{P} \mathrm{R}$ Hal., theodosio Nor.

3, 32, 2 aristaeneto $\mathrm{p} \mathrm{LM} \mathrm{Hal.,} \mathrm{aristenete} \mathrm{A}$, arestoneto $\mathrm{C}$, aristineto $\mathrm{R}$, aristinae Nor.

s domine $\mathrm{S}$, dominiae $\mathrm{P}$ Hal., domnae $\mathrm{C}$, domininae $\mathrm{R}$, dominitae Nor., dominice Frad.

4 muniano SR Hal., miniano $\mathrm{P}$, mucrano C, mutiano 2, 52, 3 Nor.

militi] 2, 52 3 SPCR Nor., militi africae Hal.

11 gaiano Coloniensis ${ }^{1}$ ) $\mathrm{R}$ Nor., galano $\mathrm{S}$, caiano $\mathrm{C}$, gallano Hal.

13 eutychio $\mathrm{M}$, euticio $\mathrm{C}$, eutichiano $\mathrm{S}$, eythithio $\mathrm{P}$, eutythio $\mathrm{R}$, cincio Nor., cytichio Hal.

14 septimae SCR Frad., septimiae P, septimae Nor., septianae Hal.

15 aurelio] C Hal., aureli $\mathrm{APR}$, fehlt in $\mathrm{S}$ Nor.

21 herodi $\mathrm{P}$ Nor., yrodeae $\mathrm{S}$, gerocli $\mathrm{C}$, ierocli $\mathrm{R}$, hierocli $\mathrm{Hal}$.

25 eugnomonio C Hal., eugomio S, eugnomano $\mathrm{P}^{\mathrm{a}}$, eugnomono $\mathrm{P}^{\mathrm{b}}$ Nor., eugnomonio $\mathrm{R}$.

3, 3, 8 hieronine $\mathrm{S}$, geroni $\mathrm{C}$, ethieroni $\mathrm{R}$, ad hieronymum Nor., etheroni Hal.

11 theodoto SC Hal., theodote $\mathrm{P}$, theodoro $\mathrm{R}$ Nor.

3, 35, 6 plinio] SPCR Nor., plenio Hal.

3, 36, 2 auitiano C, uitiano SR M Hal., latarano Nor.

${ }_{25}$ diocl. SC, dioclitiano $\mathrm{R}$, dioclae Nor., diocli Hal.

3, ss, з seuerae] W Consultatio, seuero SPCR, mauro Nor., seuae Hal.

5 frontoni et $\mathrm{C}$ Nor., frontonie $\mathrm{S}$, frontini et $\mathrm{P}$, frontino $\mathrm{R}$, frontino et Hal.

glaphirioni $\mathrm{C}$, gallaphyroni $\mathrm{S}$, gapirioni $\mathrm{P}$, gaphirioni $\mathrm{R}$ Hal., gaphini Nor.

11 gerulo (caerulo Hal. Sichardus am Rande zum Th.) rationali trium prouinciarum $\mathrm{Th}$. Hal, cyrillo $\mathrm{S}$, gerilo $\mathrm{C}$, cerylo $\mathrm{R}$, acerilo Nor.

3, 42, 6 polemonidi] SPCR, palemoni Nor., palemonidi Hal.

3, 44, 1 dionysiae $\mathrm{S}$, dioniae $\mathrm{C}$, doniae $\mathrm{R}$, donicae Nor., doritae Hal.

1) Vgl. Rheinisches Museum N. F. 45 S. $361 \mathrm{f}$. 
3, 44, 3 primo SC, rimo PR Hal., runo Nor.

4 licinio] SCR Nor., luciano Hal.

4, 5, 6 mnaseae Hal., nasee $\mathrm{W}$, mnaseas $\mathrm{Q}$, masea $\mathrm{S}$, maseas $\mathrm{P}$, mnasi $\mathrm{C}$, manseas $\mathrm{R}$, naseo Nor.

4, 6, 6 curioni $\mathrm{PR}$, carioni $\mathrm{S}$, cirioni $\mathrm{C}$ Hal., cyroni Nor.

4, 7, 3 dizoni $\mathrm{PCR}$, dryoni $\mathrm{S}$, dizonti Hal, diaconi Nor.

5 bitho. promercalem] bithopro. mercalem $\mathrm{PC}^{\mathrm{a}} \mathrm{R}$ Nor., bichoporo. mercalem $\mathrm{C}^{\mathrm{b}} \mathrm{Hal}$.

4, 10, 6 maurico pC, mauricosi $\mathrm{R}$, mauricio Hal., mantico Nor.

7 euelpisto] SPR Nor., uelpisto C, dionysio Hal.

13 barsimio SPCR Nor., barsumio Hal.

4, 19, 2 eutolmio $\mathrm{S}^{\mathrm{b}} \mathrm{C}$, eutolmione $\mathrm{R}$, euutumio oder eulltulmio

$\mathrm{S}^{\mathrm{a}}$, utelin*io $\mathrm{P}^{\mathrm{a}}$, utelinoio $\mathrm{P}^{\mathrm{b}}$, eutolmi Hal., eutelono Nor.

4 achaeo $\mathrm{SPC}$, aquaeo $\mathrm{R}^{\mathrm{a}}$, achiuae Hal, acheno Nor.

4, 14, 1 iouiano S, iuliano PC, iouentiano R, iumentiano Hal., tuliano Nor.

2 baetico $\mathrm{P}$, ueticho $\mathrm{S}$, uetico $\mathrm{C}$, uetito $\mathrm{R}$, uerico Nor., bexico Hal.

4 heroni SP, hieroni C R Hal., hurom. oder huroni Nor. 4, 15, 5 nanidiae $\mathrm{S}$, nawidiae $\mathrm{PC}$, nanide $\mathrm{R}$ Hal., hauidae Nor. 4, 17, 1 macedonae SPC Nor., macedonie R, macedoni Hal.

4, 18, 2 iuliano] SCR Nor., iohanni Hal.

$4,19,2$ auluzano $\mathrm{A}^{1}$, auliizano $\mathrm{A}^{\mathrm{u}}$, aulciano $\mathrm{S}$, aulutano $\mathrm{P}$, aulozano $\mathrm{C}$, aulizano Hal., zario Nor.

16 philippo S, philippae PCR Hal., philip. Nor.

18 uiolentillae $\mathrm{pC}$, uolentille $\mathrm{S}$ Nor., uiolenitillae $\mathrm{R}$, wiolantillae Hal.

4, 20, 4 aurelio SPCR Nor., ualerio Hal.

7 ingenuo SPCR Nor., ingenuae Hal.

4, 21, a maniliano $\mathrm{SC}$, maliano $\mathrm{p}$, manilione $\mathrm{R}$, manilio Nor., mabiliano Hal.

6 luscidi S, lucidi PCR Nor., lucido Hal.

4, 22, 2 soteri SPCR, soterico Nor., soteriae Hal.

3 marinae $\mathrm{SC}$, maximae PR Hal., maximino Nor.

4, 23, 1 sisolae $\mathrm{PC}$, sulae $\mathrm{S}$, sicolae $\mathrm{R}^{\mathrm{a}}$ Nor., sciolae Hal.

2 auluzano $\mathrm{L}\left(\mathrm{L}^{\mathrm{b}}\right.$ ? $) \mathrm{C}$, aulozona $\mathrm{S}$, aulizano $\mathrm{L}^{\mathrm{a}}$ ? Hal., alizano R, elizano Nor.

3 soterae $\mathrm{SCR}$, sotorae $\mathrm{P}$, soteri Nor, soteriae $\mathrm{Hal}$. 
4, 24, 12 heraisco ACR, zanco oder ianco S, erusco Nor., etrusco Frad, herisco Hal.

4, 26, 9 diogenio $\mathrm{PC}$, dionisie $\mathrm{S}$, diogeni $\mathrm{R}$ Hal., diogono Nor.

4, 29, 7 uiuiano SpCR, uimano Nor., auiniano Frad., uiniano Hal.

12 sepiducae $\mathrm{PC}$, sepeduce $\mathrm{S}$, sepuduce $\mathrm{R}$, sepio duci Nor., sepidutae Hal.

5, 10, 1 tatiano] SCM Nor., laciano P, ad tatianum Hal.

5, 11, 1 claudio] C Nor., claudiae SM Hal. ${ }^{1}$ ).

s claudio] SCM Nor., claudio p. p. $\mathrm{R}^{\mathrm{b}}$ Hal.

5, 12, 2 alcibiadi] $\mathrm{CM}$, alcibiadidi $\mathrm{S}$, alluniuadis $\mathrm{U}$, alabiadi Nor., alluuiadi Hal.

5, 14, 1 nicae $\mathrm{SR}^{\mathrm{b}} \mathrm{U}$ Hal. lex gemina, niceae $\mathrm{CM}$ Nor., nicetae $\mathrm{P}$.

5, 16, 1 tryphaenae] M Hal., triphime S, triphone C Nor.

10 ueriano] SPT, ualerio $\mathrm{C}$, ueriniano $\mathrm{M}$ Nor., ualerio $\mathrm{C}$, ualeriano Hal.

21 cacaliae $\mathrm{S}$, caucaliae $\mathrm{C}$, mucaliae $\mathrm{N}$, mancaliae $\mathrm{M}$ Hal., mancaliae Nor.

22 arsinoae] $\mathrm{N}$, arsinae $\mathrm{S}$, asinoen $\mathrm{M}$, asmoen $\mathrm{C}$, ad synoen Nor., archinoae Hal.

5, 17, 1 abitiane $\mathrm{S}$, abutianae CM Nor., abutiniano $\mathrm{r}$, abutinianae Hal.

s scyrioni $\mathrm{S}$, schirioni $\mathrm{PR}$, sirioni $\mathrm{M}$, michroni $\mathrm{C}$, sicioni Nor., sehironi Hal.

5, 17, 7 ad delmatium $\mathrm{S}$, ad malmatium $\mathrm{R}$, ad almachium $\mathrm{C}$, ad malinacium Nor., ad dalmatium $Q$, dalmatio Hal.

9 theodoro] SCR? Nor., theodoro p. p. Hal.

$5,18,1$ geminae SC, germiniae Nor., germillae R Hal.

${ }_{10}$ epigono SQ Hal., epigo M, epygonio C, epigorio R Nor.

11 mariniano] SM Hal. Th., mariano PCR, maximiano Nor.

5, 19, 1 mariniano pp.] SQ Hal. Th., mariano pp. CR, rufinae Nor.

5, 21, 1 polydeucae] $\mathrm{PQ}^{2}$ Hal., polidoche $\mathrm{S}$, polideuci $\mathrm{C}$, pollidencae $\mathrm{R}$, pollidente Nor.

1) Das Rescript ist an den Ehemann gerichtet. 
5, 21, 3 quartioni SPR Nor., quartino C Hal.

$5,23,1$ didae] $\mathrm{SpR}$ Nor., didiae C Hal.

$5,25,3$ tatianae] VSPCR Nor., titianae Hal.

5, 27, 2 anthemio] $\mathrm{VR}^{\mathrm{b}} \mathrm{M} \mathrm{Th}$, , antonomio $\mathrm{R}^{\mathrm{a}}$, antonomie $\mathrm{C}$, antenno Nor., antemonio S Hal.

$5,28,3$ gorgiae] VM, cordiae SR, gordie $\mathrm{C}$, georgiae Nor., gordio et aliis Hal.

5 daphno] VM, daphono S, daphnos R, damnae Nor., daphine Frad., daphnae Hal.

6 domnae] $\mathrm{V}^{\mathrm{b}} \mathrm{M}$ Hal., domna $\mathrm{V}^{\mathrm{a}}$, domine SPR, damnae Nor.

5, 30, 2 asclepiodoto] SM Hal., ascepiodoro R, asclepiodo C Nor., asclepiodoro Frad.

4 domnino C Hal., domino S, donino $\mathrm{P}$, domo $\mathrm{R}$, domno Nor.

6 otaciliae $\mathrm{R}$ Hal., othacillae $\mathrm{S}$, otalice $\mathrm{C}$ Nor., otalicio Frad.

5, 33, 1 pu.] Q Hal. Th., pp. SCR Nor.

5, 34, 1 ambibulo] SC, bibulo $\mathrm{R}$, bubulo Nor., amphibulo Hal. 5 aelianae] VSCR Nor., aemylianae Hal.

8 euelpisto] VP Hal., euellsisto S, eunelpisto M, helpisto $\mathrm{C}$, eumelphio $\mathrm{R}$, eumelfi Nor.

13 monaxio] C Hal., menaxio R Frad., maximo S, menaio Nor.

$5,35,1$ otaciliae] Q Hal, otatilie $\mathrm{M}$, othalicie $\mathrm{S}$ Nor., octadiae $\mathrm{P}$, octaciliae CR.

5, 36, 4 euploio] Q Hal. 5, 42, 2, eupolitio S, euphebo CR, euplogio M, enplĩo Nor.

5, 37, 9 melitiae VM, mellitae SQ, militiae CR Nor., inclytae Hal.

5, 39, 1 septimo S Nor., septimio CR Hal.

2 sosandro $\mathrm{CR}$, synandro $\mathrm{S}$, zodandro $\mathrm{P}$, zonandro Nor., sorachoro M, sorarcho Hal.

5, 40, 1 melthiadi $\mathrm{S}$, militiadi $\mathrm{C}$ Nor., casio mileti $\mathrm{R}$, cassio militi Hal.

5, 42, 2 euploio] VQT Hal., euphoio S, eupoloio C, eupolio R, euproio M, euploro Nor.

5, 43, 9 ammiano $\mathrm{CR}$, ham- V, hammiano Hal., anumano Nor., damiano S, damia. Frad. 
5, 44, 1 miltiadi Hal., meltiadi SC, militiadi PR Nor.

2 euaristo S, euaresto PCR Hal., enarecto Nor.

5, 31, s septimo et cononi (hononi $\mathrm{S}$ )] VSC, cononi etc. Nor., cononi et aliis Hal.

11 chrysianae] VR, casiane C, crosiane Nor., chrusiano M Hal.

$5,56,1$ praesentino] VSPCR Nor., crescentino Hal.

$5,60,1$ hermillae] SCR, ermile M Nor., hernulae Hal.

5, 62, 6 maximo S Nor., max. L, maximiano C R Hal.

20 charitino] SCR, carino Nor., cratino Hal.

$5,63,2$ auluzano $\mathrm{CR}^{\mathrm{a}}$, auligiano $\mathrm{S}$, aulicano $\mathrm{R}^{\mathrm{b}}$ Nor., aulizano Hal.

5, 64, 1 guttio S W Hal., gutio M, guteo Nor., gurtio R Frad., gratio $\mathrm{C}$.

2 reginio $\mathrm{C}$ Hal., regnio $\mathrm{S}$, regioni $\mathrm{L} \mathrm{R}$ Frad., regno Nor.

5, 70, 1 marinianae $\mathrm{CM}$ Hal., marine $\mathrm{S}$, marianae $\mathrm{R}$, mırtianae L Nor.

5, 71, 2 clearcho et aphrodisio (effrod. Nor.)] SCR Nor., clearcho et aliis Hal.

13 zenonillae] VPCR, zenoni S, zenonille Nor., zenolae Hal.

14 frontoni SM, phrontonio VCR, frontinio Nor., phrominio Hal.

5, 72, 1 ualenti SPCR Nor., ualentino Hal., ualentini M.

6, 2, 6 pythodoro PCR Nor., philodoro S, pythidoro Hal.

8 ualenti SPC Nor., ualentino Hal.

9 aedesio PC, hesidio S, edisio $\mathrm{R}$ Hal., dedisio Nor.

15 socratiae $\mathrm{SPC}$, socratae M Hal., socranae R Nor.

16 et aliis] PCR Hal., om. SM Nor.

18 dionysodoro] SPCR, dionoscodoro Nor., dionysiodoro

Hal.

19 nesitheo $\mathrm{C}$, mencstheo $\mathrm{P}$, nestieo M Hal., mennae $\mathrm{R}$, theofalsus S, anesteo Nor.

6, 3, 9 letorio $\mathrm{C}$, lytorio $\mathrm{S}$, litorio $\mathrm{M}$ Nor., latario $\mathrm{R}$, lictorio Hal.

13 pp.] M Hal., ppm. S, m. R, om. C Nor.

6, 7, 2 pu.] VP Hal., $p p$. SCR Nor.

$6,14,3$ comitem orientis] VSCR Frad., comitem r.p. orientis Hal., om. Nor. 
6, 16,1 iulio S Nor., iul. V?, iuliano CR Hal., iuli. Frad.

6, 19, 1 theodotiano] VSR, thodotiano Nor., theodo. Frad., theodosiane $\mathrm{C}$, theodosiano M Hal.

$6,20,10$ ireneae $\mathrm{C}$, herenee $\mathrm{S}$, bireneae $\mathrm{P}$, hirineae Nor., hirenae Hal.

12 nilanthiae PR Frad., nilathiae $\mathrm{C}$, nilontio $\mathrm{S}$, dilanciae Nor., philantheae Hal.

6, 21, 5 sozomeno] VST Hal., zogomeno C, zoxomeno R, semozeno Nor.

6 ualenti VSR Nor., ualentino C Hal.

8 aeternio VSCR, etrinio Nor., aeterno Hal.

11 aemilio CR Frad, aemiliano S Hal., emil. Nor.

14 maximae SR Nor., max. V, maximi $\mathrm{C}$ Hal.

6, 22, 6 pu.] V $\mathrm{V}^{\mathrm{b}}$ Hal., pp. SC Nor.

10 iuliano] VSPCR Nor., iohanni Hal.

6, 23, 10 menophiliano VCR, moenepholiano S, menophilo Nor., menophilia Frad., menophelimo Hal.

${ }_{18}$ pu.] S Th. Hal., pp. C Nor.

25 urbis constantinopolitanae Th. Hal, fehlt in SPCR Nor.

6, 25, 4 aemilio SCR, emil. Nor., aemyliano Hal.

6, 26, 2 phronimae] Nor., afronime $\mathrm{S}$, froniamae $\mathrm{C}$, frontinae $\mathrm{R}$, frontiniae Hal.

4 firmiano Hal., firmo S, firmino CR Nor., firminio M.

6, 28, 1 fauio SC Nor., fauino R, fabiano Hal.

3 iuliano] SCR Nor., iohanni Hal.

6, 30, 7 eusebio] SCR Frad., eusebiae Nor., eusobino Hal.

16 ennodio] SPCR, ennoio Th., cymodo Nor., synodo Frad., annodio Hal.

6, 31, 1 muciano SPCR Nor., mutatio Hal.

6, 35, 6 clementino SCR, plementino P, clemientino Hal., fehlt in Nor.

6, 37, 7 fausto CR Hal., faustino S Nor.

6, 42, 1 demetrio] SCR Nor., fehlt in Hal. ${ }^{1}$ ).

c nilo SCR, iulio Nor., nilio Hal.

11 papiniano CR Nor., appiano S, papyriano Hal.

1) Wohl deshalb, weil folyt: Si probaueris Demetrium petisse, woraus Hal. macht: Demetrium si probaueris petisse. 
6, 42, 22 planciano SCR, pluciano p, plociano Nor., plautiano Hal.

24 menestrato S PCR Nor., menostrato Hal.

6, 49, 6 dioscoro] SCR Frad., dioscino Nor., dioscorio Hal.

$6,50,2$ sanctiano PCR, saciano Nor., sactiano Hal.

5 samosatae $\mathrm{C}$, samosite $\mathrm{S}$, adamositae $\mathrm{P}$, adaminosate

$\mathrm{R}$, dimosatae Nor., damasatae Hal.

6, 57,4 pp.] SCR Th., pu. PR Hal., fehlt in Nor.

6, 58, 5 cirillae Q Nor., curillae CR, cupillae Hal.

9 damagorae SCR Nor, demagorae Hal.

10 florentio] S Nouella, ad florentium PCR Hal., ad florianum Nor.

6, 60, 2 florentino M Th., florentio S L CR Hal., floro Nor.

6, 61,5 nepoti] SCR Nor., nepotiano Hal. Addenda, fehlt in Hal. Text.

7, 73, 4 quinto $\mathrm{R}^{\mathbf{b}} \mathrm{M}$ Hal., cohinto $\mathrm{SC}$, cointo $\mathrm{W}$, conto Nor.

5 magnae] SCR Nor., moenae Hal.

7, 75, 1 caesiae R, cessiae C Nor., cassiae ST U Hal.

2 symphorianae] S Paris $4517 \mathrm{Hal}$, simpronianae C, sempronianae Nor.

8, 2, 3 uicario hispaniarum Th. Hal., uicario V SPCR Nor. 8, 4, 3 et proclinae] VPCR, et proculinae S Hal, om. Nor. 6 pancratio] VSCR, pangri. oder pag. ri. $\mathrm{P}$, penerario

Nor., potito Hal. aus Th. 4, 22, 2.

8, 8, 3 enodiae P Hal., eunodie S, euodio CR, enodio Nor.

$8,13,16$ heraidi $\mathrm{V}$, eranidi $\mathrm{S}$, heroidi $\mathrm{C}$ Hal., herculi $\mathrm{R}$, ercul.

Nor., heroide Frad.

20 uito] VSPCR Nor., wieto Hal.

8, 14, s alexandri a.] SR Nor., alexandriam C, alex. a.demostheni Frad., alex. a. ad demosthenem Hal.

4 aaa.] aaa. africano Hal., a. afféc. Nor.

8, 17, 10 polydeucae] VM, polideuciae $\mathrm{S}$, polucleucae $\mathrm{C}$, polido. $\mathrm{R}$, polidoro Nor., pollipeucae Hal.

8, 19, 1 endemiae PC Frad., hendemie oder heudemie S, endomiae $\mathrm{R}$, euidemiae Nor., eudemiae Hal.

8, 24, 2 nonnoso] SPCR Nor., annoso Hal.

8, 27, a cyrillo] SCR, sillo Nor., cillo Hal.

$8,29,5$ nonnae $\mathrm{SC}$, nonae $\mathrm{P}$, ñonae $\mathrm{R}$, no. Nor., noniae Hal.

$8,37,7$ antonino $\mathrm{S}$, antinio $\mathrm{P}$, antonio $\mathrm{CR}^{\mathrm{b}} \mathrm{Hal}$., anto. Nor. 
8, 40, 14 saluio CR, salmano Nor., saliuo Hal.

27 iuliano] SPC Nor., iohanni Hal.

8, 41, 6 ziparo $\mathrm{S}$ (vgl. 4, 5, 8), derziparo p C Hal., deriparo $\mathrm{R}$, derzi. Nor.

8, 42, 1 aristaenetae] VSPCR, arist. Nor., aristaeneto Hal.

14 cutae $\mathrm{V}$, gotheti $\mathrm{S}$, cretei $\mathrm{Pb}$ ?, caetae $\mathrm{C}$, coitae $\mathrm{R}$, heretae Nor., cohortae Hal.

20 eucratidi (eugr. S)] SC, eumcratidi R, eufrati Nor., eucrati Hal.

23 uatio $\mathrm{C}$, batio $\mathrm{R}$, probatio $\mathrm{S}$, bas. Nor., uacio $\mathrm{Hal}$.

8, 44, 1 munatio CR, monatio S, munitio P Hal., muciano Nor.

8 clementio SP Nor., clementino CR Hal.

$8,47,10$ iohanni] VSPCR Nor., iuliano Hal.

11 iohanni] CR Nor., iuliano Hal.

$8,50,13$ cc.] CR Nor., c. aurelio S, cc. coloniae M, cc. quartinae Hal.

15 mucatraulo $\mathrm{SD}$, cucatraulo $\mathrm{C}$, mucat paulo $\mathrm{R}$, macrac.

Nor, macrotaulo Hal.

16 basilinae SDCR, bas. Nor., basilidae Hal.

18 tryphoniano SDCR, triph. Nor., tripho. Frad., tryphiniano Hal.

19 seuerianum] SR Th., seuerinum C Hal., fan. Nor., seuer. Frad.

8, 53, 4 massiciae] Vat., marsciae $\mathrm{C}$, marciae SR Nor., marsiae Hal.

5 falconellae $\mathrm{S}$, flacconillae $\mathrm{C} \mathrm{Hal.,} \mathrm{flagonille} \mathrm{R}$, flacco. Frad., fehlt in Nor.

6 aristaenetae] Vat., aristianae LCR Frad., arestiano S, christianae Hal.

9 augustanae LCR, aug. Nor., augustie Frad., augustianae Hal.

11 sabiniano] LR Consultatio, sabiano R, sabin. Nor., sabino Hal.

14 ideae $\mathrm{C}$, ide $\mathrm{L}$, idiae $\mathrm{R}$, idaeo Hal., tacio Nor.

${ }_{20}$ heluio] aelbio L, helbio $\mathrm{R}$, helmio $\mathrm{C}$, paulo Nor., helinio Hal.

8, 55,3 felici] LCR Frad., fe. Nor., felicio Hal.

8, 56, 1 daphenae] 4, 48, 3, daphetie $\mathrm{L}^{\mathrm{b}}$, daphnae $\mathrm{C}$ Hal., dapnae

$\mathrm{R}$, ad populum Nor.

4 iohanni] CR Nor., iuliano Hal.

9, 1, 9 seueriano LCR, seuero Nor., seueriae Hal. 
9, 110 mucatraulo] mucatrabio LC, mucrataulo R, macha. Nor., buccatrahio Hal.

16 callitico LCR, callutico Hal., car. Nor., galitico M Frad.

9, 4, 2 euagrium] LCR Th., euagrium pp. Hal., uagum Nor.

9, 9, 4 procons. narbonensium $\mathrm{pCR}$, procons. narbonen. prouinciae Hal., procura. carb. Nor.

7 herculano LCR, iul. Nor., heruclano Hal.

8 domnae $\mathrm{CR}$, donne L, domno D Hal., felici Nor.

11 norbano LCR, narbono Nor., naruano Hal.

15 hilariano $\mathrm{C}$, hilario $\mathrm{R}$, illiri Nor., hilarino Hal.

21 silano LR, siliano C Nor., siluano M Hal.

22 obrimo $\mathrm{C}$, obrimi $\mathrm{L}$, obrimosi $\mathrm{R}$, obsimo Nor., oblimosi Hal.

9, 12, 1 peliae C, praeliae L, peliciae R Hal., pelio Frad.

6 procons. africae] Th. Hal., om. LCR Nor.

7 pu.] Th. Hal., om. LCR Nor.

8 ad albinum pp.] Th. Hal., om. LCR Nor.

9 aureliano] LC Nor. Th., aurelio R Hal.

9, 16, 3 munacio L, monatio CR Hal., manacio Nor.

5 agathocli $\mathrm{L}$, agatodi $\mathrm{R}$, agatho $\mathrm{C} \mathrm{Hal.,} \mathrm{agorio} \mathrm{Nor.}$

9, 18, 1 a.] LCR Nor., a. titio Hal.

5 a. LCR Nor., a. et iulianus c. Th. Hal.

9, 20, 8 constant. $\mathrm{R}$, const. C, constantino $\mathrm{M}$, considio Hal., fehlt in Nor., eidem Frad.

11 ampliatae RQW, ampiatae $\mathrm{C}$, praeliatae Nor., marpiatae Hal.

9, 22, 21 hilariano correctori luc. et brittiorum (hirtiorum $\mathrm{R}$, brutiorum Hal.)] CR Hal., correctine luc. Nor.

9, 23, 5 gallicano CR, gallo Nor., gallieno Hal.

9, 24, 2 procons. afric.] Th., pp. LCR Hal., fehlt in Nor.

9, 27, s c.r.p.] Hal. Th. B, $p p$. CR Nor.

9, s0, 1 florentio praef. (pp. C) aug.] LCR Th., floro Nor., florentio p. u. Hal.

9, 32, s sulpicio CW, sup. Nor., supplicio L R Frad., simplicio Hal.

9, 34, 4 euprepeti LR, eutrepeti C, eutropio Nor., euprepio Hal. 9, 35, 2 dauo L, dabo R, claud. Nor., clau. Frad., clauo R Hal.

4 uindi LC Nor., iudio R, uindio Lips. I Hal. 
9, 35, 7 paenentiano LCR, potentiae Nor., potentiano Hal. 9, 38, 1 pp.J $\mathrm{CR}^{\mathrm{b}} \mathrm{Th}$. Nor., fehlt in Hal. 9, 41, 1 antigono] Dig. 48, 18, 1 6, antigonae LCR Frad., antig.

Nor., antianae Hal.

9 carisium LCR, carissimum Hal., cat. Nor.

${ }_{16}$ antonium] LR Th., antoninum C Hal., anto. Nor.

9, 43, 1 lyciae $\mathrm{R}$, prouinciae LCWQ, ciliciae Hal., linciae Lips. I, fehlt in Nor.

9, 44, 1 uicario] LCR Th. Frad., uict. Nor., uic. asiae Hal. ${ }^{1}$ ).

Von diesen selbständigen Lesarten Haloanders dürfen wir zunächst diejenigen bei Seite lassen, welche anscheinend selbsterfundene Verbesserungen sind ${ }^{2}$ ). Einiges mag auch Druckfehler sein, z. B. zu 1, 7, 3. 2, 11, 13. 3, 27, 2. 3, 35, 6. 6, 35, 6. 6, 42, 24. 8, 40, 14. Haloander hat auch, wie schon oben hervorgehoben, die Ausgabe des Codex Theodosianus von Sichardus zur Verbesserung des justinianischen Codex herangezogen ${ }^{3}$ ); daher stammen seine Lesarten in $3,38,11.6,23,18.20 .8,2,3$. 8, 4, 6. 9, 12, 6-8. 9, 18, 1. 5. Ferner hat Haloander aus nicht ersichtlichen Gründen die Adressaten der justinianischen Konstitutionen vertauscht in $1,5,19.2,58,2.3,28,33.4,18,2.6$, 22, 10. 6, 28, 3. 8, 40, 27. 8, 47, 10.11. 8, 56, 4). Endlich darf auf die Vertauschung der beiden Abkürzungen pp. (praefectus practorio) und pu. (praefectus urbi) kein Gewicht gelegt werden; durch die häufige Wiederkehr dieser Abkürzungen sind vielfache Verwechslungen derselben herbejgeführt worden ${ }^{5}$ ), und so konnte es leicht kommen, dass durch nochmalige Verwechslung in einer weiteren Abschrift die richtige Lesart wiederhergestellt wurde. Darum möchten solche Stellen, wie $1,5,6.1,14,1.1,19,2$. 6. $2,17,16.3,1,10.5,33,1.6,22,6.6,23,18$

1) Vgl. S. 289. - 2) Wie arg die Subscriptionen Haloanders durch derartige Besserungen entstellt sind, ist in meiner Vorrede S. XXX f. nachgewiesen; vgl. auch Seeck im Rheinischen Museum Neue Folge 41 S. 161 f. - $\left.{ }^{3}\right)$ Vgl. hinsichtlich der Subscriptionen meine Kritik des just. Codex S. 20 und meine Vorrede zur Ausgabe S. XXXI Anm. 2. 4. - ) Ob alles dies auf Haloander zurückgeht, oder auch auf den Egnatianus, lasse icb dahingestellt, umsomehr als auch unseren Handschriften derartige Verwechslungen nicht ganz fremd sind; vgl. meine Vorrede s. XXIV, 2. - s) Andererseits ist $p p$. bisweilen unrichtig zugesetzt, vgl. meine Vorrede S. XXIV Anm. 3 und hinsichtlich Haloanders 1, 10, 1. 1, 22, 3. 1, 54, 2. 3. 2, 52, 5. 5, 11, 3. 5, 17 , 9 . 
für die Werthschätzung des Egnatianus nicht ausschlaggebend $\left.\operatorname{sein}^{1}\right)$.

Bringen wir alles dies in Abzug, so bleibt doch im Verein mit den oben S. $294 \mathrm{ffi}$. aufgezählten Verbesserungen des älteren Textes eine so reiche handschriftliche Ausbeute im Verhältniss zu den Abschnitten, in welchen der Egnatianus fehlte, dass wir dem letzteren das Hauptverdienst an diesem Gegensatz zuschreiben müssen ${ }^{2}$ ). Wenn auch im einzelnen Fall der Zweifel berechtigt ist, ob dieser oder eine andere Handschrift benutzt worden, so wird doch der Gesammteindruck der Adressen Haloanders einen Rückschluss auf die Beschaffenheit des Egnatianus gestatten.

Vergleichen wir nun Haloander mit den einzelnen Handschriftenklassen, so wird zunächst, soweit die Veroneser Handschrift $(V)$ in Betracht kommt ${ }^{3}$ ), kein Zweifel sein, dass der Egnatianus diesem nicht ebenbïrtig ist. In keiner Stelle bietet Haloander einen besseren Text, wohl aber in vielen einen schlechteren. Aehnlich fällt der Vergleich mit der Summa Perusina aus; es giebt zwar Stellen, in welchen diese die Adresse in verdorbener Gestalt überliefert und Haloander die bessere Lesart hat ${ }^{4}$ ), aber ungleich viel mehr solcher, in denen Haloander der Summa nachsteht.

Die Hauptfrage ist, wie verhält sich der Egnatianus zu den Handschriften der Epitome aucta, insbesondere zur Pistojeser (P) und Pariser (L) Handschrift, ferner zu den Bononi-

1) Vgl. im Gegensatz dazu 2, 57, 2. 3, 23, 1. 6, 37, 4. - 2 ) In einem kleineren Abschnitt 3,36,3-23, wo Haloander sich im Gegensatz zu den voraufgehenden und nachfolgenden Stellen lediglich auf die älteren Ausgaben stützt, dürfen wir daraus und dass diese Konstitutionen bei ihm ohne Subscriptionen sind, auf eine Lücke im Egnatianus schliessen. Dagegen muss ich die früher (Kritik S. 20) aufgestellte Vermuthung zurückziehen, dass die Titel 1, 27-29, zu welchen Haloander gleichfalls keine Subscriptionen giebt, im Egnatianus gefehlt hätten, denn innerhalb derselben finden sich Besserungen der Adressen, welche zweifellos auf eine Handschrift zurückgehen, und mein Bedenken wegen Fehlens der Notitiae zu 1,27,1.2 erledigt sich durch die folgende Untersuchung über das Verhältniss des Egnatianus zu den Vulgathandschriften. $-{ }^{3}$ ) Vgl. 5, 25-28. 5, 34. 37. 42. 51. 56. 71. 6, 7, 19. 21-23. 8, 2. 4. 42. 47. - 4) 2, 4, 26. 28. 33. 2, 43, 3. 5, 28, 6. 5, 30, 4. 5, 34, 8. 13. 5, 36, 4. 5, 42, 9 . $6,2,16.8,42,23$. 
enses oder Vulgathandschriften. Beide Gruppen lassen sich in dieser Beziehung nicht aus einander halten, denn in die Handschriften der Epitome sind viele Lesarten aus den Handscliriften übertragen, aus denen die Bononienses durch $\mathrm{Er}$ gänzung der Epitome hervorgegangen, während einzelne der Letzteren hin und wieder den Text der Epitome unverändert ïbernommen haben. Stellen wir nun diejenigen Adressen, in welchen Haloander die Ueberlieferung dieser beiden Handschriftengruppen berichtigt, denen gegenüber, in welchen er eine schlechtere Lesung giebt, so wird man wiederum finden, dass die letzteren jene überwiegen ${ }^{1}$ ). Auch jede einzelne der von mir benutzten Vulgathandschriften, selbst die Handschrift von Montpellier (M), welche dem Casinas und der Berliner Handschrift 273 als minderwerthig gegenübersteht, hält dem Egnatianus die Waage.

Damit ist die Wahrscheinlichkeit gewonnen für die Vermuthung, welche ich in der Vorrede zu meiner Ausgabe Seite XII geäussert habe, dass der Egnatianus zu den Vulgathandschriften zweiten Ranges gelört habe; eine Bestätigung dieser Annahme darf auch darin gefunden werden, dass Haloander in vielen Stellen die verdorbenen Lesarten der Nürıberger Ausgabe beibehielt. Es wird genügen, hier die Beispiele bis zur ersten grösseren Lücke des Egnatianus im vierten Buch zusammenzustellen ${ }^{2}$ ):

1) Beispielsweise mögen hier diejenigen Stellen zusammengetragen werden, wo Haloander die Lesarten von $C R$ berichtigt: 1, 9, 1. 1, 14,9. 1, 24, 4. 1, 40, 5. 2, 3, 15 (wenn nicht etwa hier der Adressat Pactumeio Erfindung und aus dem folgenden Pactum gebildet ist). 2, 4, 26. 2, 7, 25. 2, 11, 1. 20. 2, 12, 1. 2, 16, 2. 2, 43, 3. 2, 50, 3. 3, 1, 6. 4, 5, 6. 5, 14, 1. 5, 19, 1. 5, $21,1.5,28,6.5,30,2.5,34,8.5,36,4.5,64,1.6,21,5.7,75,2.9,27,5 . \quad$ In allen diesen Stellen mit Ausnahme der letzteren, auf welche ich unten zurückkomme, findet sich Haloanders Lesart in der einen oder der anderen minderwerthigen Vulgathandschrift. Umgekehrt tritt Haloander hinter $C R$ zurück in $1,5,2.1,6,3.1,9,12.13 .1,12,2.1,22,1.1$, 29, 1. $1,55,4$. $2,4,13.42$. $2,12,10$. 2, 18, 5. 14. 15. 21. 2, 19, 4. 2, 20, 5. $2,22,1$. $2,26,4$. $2,30,1.2$. $2,31,1$. $2,44,1$. $2,50,4$. 3, 11, 3. $3,28,20$. 3, 29, 2. 3, 38, 3 . $3,44,1.4,7,5.4,14,2.5,25,3$. 5, 28,5 . 5, 34, 1. 5. 5, 37, 9. 5, 39, 2. 5, 62, 20 . $6,20,12.6,30,7.6,31,1.6,49,6.6,58,5 . \quad 8,13,20$. $8,24,2$. $8,27,9.8,29,5$. $8,42,14.8,50,13.18 .8,53,6.20 .9,1,9.10 .9,30,1.9,34,4.9,41,1.9 .-2)$ Für die erste Hälfte des fünften Buches vgl. Kritik des just. Codex. S. 81 f., nämlich $5,11,2.5,12,3.9 .22 .5,28,4$. 5, 34, 3. 5, 37, 20. 
1, 11, 3 uicario fehlt.

1, 14, 6 florentio] florentino.

$1,15,1$ eusignium] eugenium.

$1,20,1$ praefecto augustali] $p . p$.

$1,26,1$ theodoto] theodoro.

1, 28, 3 pu. fehlt.

1, 29, 2 per orientem. Apparitores] Apparitores per orientem.

1, 31, 2 principium] patricium.

1, 32, 1 sacrarum largitionum fehlt.

1, 36, 1 pusaeo] useo.

$1,46,1$ comitibus et magistris] magistris et comitibus.

2, 4, 2 lutatiae] luctatio.

$2,18,20$ octauiae] octauianae.

2, 29, 1 theodotae] theodorae.

2, 42, 2 uitalio] uitaliano.

3 theodotae] theodorae.

2, 48, 1 liciniano] licinio.

2, 54, 1 catulo] attalo.

$3,3,2$ dicunt] uicariis (aus c. 1).

$3,9,1$ ualenti] ualente.

3, 20, 1 messiae] messalae.

3, 26, 9 uicarium] uirum clarissimum.

$3,28,7$ secundino] secundo.

22 statillae] tantillae.

$30 \mathrm{pp}$. fehlt.

3, 32, 6 austronio] ustronio.

3, 38, 4 maximum] maximianum.

$3,44,10$ aquilinae] aquilianae.

$4,2,12$ theophano] theophanio.

$4,6,3$ alexandro] alexandrae.

$4,7,7$ zenonidae] zenoni.

$4,20,12$ aa.] aa. georgiae.

$4,21,11$ theageni] teagenae.

$4,24,3$ uictori] uictorino.

Gegenüber der Menge dieser Stellen und bei der daneben so sichtlich hervortretenden Benutzung des Egnatianus wäre die Erklärung misslich, dass überall nur Nachlässigkeit Halo- 
anders vorliege; man wird vielmehr zu der Annahme gedrängt, dass der Egnatianus entweder mit der Nürnberger Ausgabe übereinstimmte, welche ja auch den jüngeren Bononienses nahesteht, oder dass er zum Theil noch fehlerhaftere oder verstiummeltere Adressen wie die Ausgabe hatte.

Dass aber der Egnatianus mit unseren Handschriften verwandt ist und nicht für sich eine selbstständige Handschriftenklasse bildet, das ergiebt sich mit Sicherheit aus der Uebereinstimmung Haloanders mit denselben in einzelnen Fehlern ${ }^{1}$ ).

So mit $P$ in $2,45,2.3,32,13.8,44,1$;

nit $P C R$ oder $A C R$ in $1,5,1.3,28,27,28$;

mit $P R$ in $2,26,3.3,44,1$;

mit $C R$ in 1, 48,2. 2, 2, 1. 2, 3, 14. 3, 32, 21;

mit $C$ in $1,5,4.5,21,3.5,23,1.8,13,16.8,50,19.8,53,20$, vgl. 9, 16,5 ;

mit $C^{b}$ in $4,7,5$;

mit $R$ in $3,31,3.3,33,8.4,14,1.5,40,1.6,26,2$. $9,9,22$;

mit $r$ in $5,11,3.5,17,1$;

mit $M$ in 1, 23, 3. 1, 54, 2. 2, 12, 10. 3, 13, 3. 3, 15, 2. 5, 16, 21. 5, 39, 2. $5,72,1.6,2,15.19 .6,19,1$.

Wir werden damit hinsichtlich der Benutzung des Egnatianus für die Adressen auf denselben Weg gewiesen, der sich fïr die Benutzung der jüngeren Bononienses als der allein gangbare erwiesen hat ${ }^{2}$ ). Wie diese in meiner Ausgabe zur Aushülfe herangezogen sind, wo ausnahmsweise $C R M$ (oder $C M N$ ) die erkennbar bessere Ueberlieferung nicht bewahrt haben, so könnte das Gleiche mit Haloanders Ausgabe geschehen ${ }^{3}$ ). Dass solch eine sporadische Benutzung die Gefahr des Uebersehens in sich birgt, liegt auf der Hand; wie gering sie im vorliegenden Falle ist, zeigt sich daran, dass unter allen S. 296--311 aufgeführten Stellen nur zwei sich finden, in denen

1) Dass sich daneben auch eine Verwandtschaft mit der Summa Perusina $(S)$ verfolgen lässt $(1,7,1.5,27,2.7,75,1$, vgl. auch $2,19,6$. 3, 23, 11. 8,4,3), führt nur darauf, dass eine der Mutterhandschriften, welche zur Ergänzung der Epitome dienten, mit $S$ verwandt war, wie sich eine gleiche Verwandtschaft zwischen dem Veronensis und einer dieser Mutterhandschriften verfolgen lässt, vgl. meine Vorrede S. XXXIV. - 2) Vgl. meine Vorrede S. XXXVII. - 3) Vgl. in meiner Ausgabe z. B. $1,22,2$. 
Haloander allein von der besseren Lesart Zeuguiss ablegt ${ }^{1}$ ), nämlich in $9,27,5$, wo c. $r . p$. gegenüber dem $p p$. der bisher verglichenen Bononienses clurch den Theodosianus und die Basiliken bestätigt wird ${ }^{2}$ ), und $9,43,1$, die Stelle, von welcher Momınsens Untersuchung ausgegangen ist. Dass der Egnatianus sich im neunten Buch gegenüber den handschriftlichen Hülfsmitteln so ergiebig erweist, kommt daher, dass hier die Summa Perusina und der Pistoriensis versagen und dass die übrigen bis jetzt verglichenen Handschriften in diesem letzten Buch die Adressen mehr als vordem vernachlässigt haben ${ }^{3}$ ). Sollten also die sachlichen Bedenken Mommsens gegen den consularis Lyciae der Berliner Handschrift unabweisbar sein ${ }^{4}$ ), so würde die Lesart Haloanders als genügend beglaubigt gelten köunen. Auch halte ich die Möglichkeit nicht für ausgeschlossen, dass die Haloandersche Ueberlieferung beider Stellen noch in einem oder dem anderen der jüngeren Bononienses auftaucht, wie ja auch die Lücke in 9, 19,6 schon durch eine Leipziger Handschrift ausgefüllt wird.

1) Auf die leicliten Aenderungen in 1, 9, 1, 5, 42, 2. 5, 44, 1. 6, 23, 18 wird kein Gewicht zu legen sein. Der Zusatz Haloanders in 9, 8, 6 zur Inscription Paulus (libro singulari) de publicis iudiciis scheint lediglich aus dem Titel des Werkes in den Digesten entlehnt als Parallele zur folgenden Inscription: Marcianus libro I de publicis iudiciis. - ${ }^{2}$ ) Unmöglich ist es übrigens nicht, dass Haloander durch den Inhalt der Konstitution und durch die Worte spectabilitatis tuae auf den comes rerum privatarum geführt wäre. - ${ }^{3}$ ) Vgl. aus der obigen Zusammenstellung 9, 12,6-8. 9, 24, 2, ferner noch folgende Stellen, zu denen Haloander keine selbstständigen Lesarten giebt: 9, 19,6. 9, 26, 1. 9, 27, 4. 9, 39, 8 . - 4) Die Titulatur consularis ist wohl unverändert aus dem Codex Gregorianus übermommen; dass aber der Verfasser dieser Sammlung den consularis nicht im Rescript vorgefunden hat, ist von Mommsen hervorgehoben. Fs wird sich also tragen, ob sejner Zeit, d. h. unter Diocletian, Lycien provincia consularis gewesen, beziehungsweise mit einer solchen vereinigt war. Unter Justinian gehörte Lycia zu den provinciae consulares (Nov. 8 notitia $\$ 32$ ); zur Zeit der Notitia (Or. 1, 100) stand es unter einem Praeses. 